\title{
Identitas Keindonesiaan dalam Pidato Soekarno pada 1 Juni 1945
}

\author{
Anang Sujoko ${ }^{1}$, Fidelis Aggiornamento Saintio ${ }^{2}$, Dicky Wahyudi ${ }^{3}$ \\ ${ }^{123}$ Magister Ilmu Komunikasi, Fakultas Ilmu Sosial Ilmu Politik, Universitas Brawijaya \\ Jl. Veteran Malang 1, Malang, Jawa Timur, 65145, Indonesia \\ Email: anangsujoko@ub.ac.id ${ }^{*}$; aggiorn@gmail.com²; dickywahyudi366@gmail.com³ \\ ${ }^{*}$ Corresponding author
}

\begin{abstract}
Colonialism eliminates Indonesian identity and personality because colonialism is synonymous with cultural hegemony and stereotypical thinking. To fight this practice, Soekarno has pioneered ideas that highlight the identity of the Indonesian nation. The crystallization of this thought was contained in a speech on June 1, 1945. The purpose of the research was to dismantle the third space of communication in Soekarno's speech in building the identity of the Indonesian nation. This study uses hermeneutic analysis to find out what efforts were made by Soekarno to find the identity of the Indonesian nation. The results of this study indicate that the June 1, 1945 speech is a shared communication space to facilitate different values and cultures in Indonesia. The meeting of values and culture ultimately led to the discovery of national identity and narratives to fight the hegemony of colonialism. This research contributes to the enrichment of the concept of the third space of communication as a study of Communication Science on the phenomenon of communication in Indonesia. Keywords: Colonialism; Soekarno; Third Space of Communication; Hermeneutic
\end{abstract}

\begin{abstract}
Abstrak
Kolonialisme menghilangkan jati diri dan kepribadian Indonesia, karena penjajahan identik dengan hegemoni kebudayaan dan pemikiran stereotip. Untuk melawan praktik ini, Soekarno telah merintis pemikiran yang menonjolkan identitas bangsa Indonesia. Kristalisasi pemikiran ini tertuang dalam pidato 1 Juni 1945. Tujuan dari penelitian untuk membongkar third space of communication pidato Soekarno dalam membangun identitas bangsa Indonesia. Penelitian ini menggunakan analisis hermeneutika untuk mengetahui usaha apa yang dilakukan oleh Soekarno untuk menemukan identitas bangsa Indonesia. Hasil penelitian ini menunjukkan bahwa pidato 1 Juni 1945 adalah ruang komunikasi bersama untuk memfasilitasi nilai-nilai dan kebudayaan yang berbeda di Indonesia. Pertemuan nilai dan kebudayaan tersebut pada akhirnya berujung pada penemuan identitas bangsa dan narasi untuk melawan hegemoni kolonialisme. Penelitian ini berkontribusi pada pengayaan konsep third space of communication sebagai kajian Ilmu Komunikasi pada fenomena komunikasi di Indonesia. Kata kunci: Kolonialisme; Soekarno; Third Space of Communication; Hermeneutika
\end{abstract}

\section{Pendahuluan}

Hegemoni dan stereotip merupakan praktikpraktik dari nilai kolonialisme (Bhabha, 1994), yang mengglorifikasi dan memosisikan bangsa penjajah superior dan bangsa terjajahinferior, baik secara sikap, perilaku, dan pemikiran (Soekarno, 1964a:188). Praktik hegemoni membuat bangsa terjajah selalu berada dalam kekuasaan dominasi dari bangsa penjajah, dan jejak hegemoni dari bangsa penjajah selalu meninggalkan penga ruh terhadap bangsa yang terjajah (Fennell, 2018; Rodriguez, 2018) - pengaruh tersebut meliputi 4 hal, yakni politik, budaya, tekstual, dan identitas (Said, 2010). Penjajahan tidak lagi menjadi soal penghisapan sumber daya, tetapi juga mengarah pada kontrol cara berpikir terhadap suatu bangsa - alhasil menentukan posisi bangsa yang superior dan bangsa yang inferior.

Wacana tentang hegemoni dapat ditemukan di dalam beberapa karya-karya besar yang membahas poskolonialisme, salah satunya karya dari Edward W. Said (2010) yang mengeksplorasi diskursus poskolonialisme antara Barat dan Timur. (Said, 2010) menganggap penjajahan yang dilakukan oleh bangsa Barat telah memunculkan hegemoni yang mempengaruhi kehidupan Timur sebagai bangsa yang terjajah. Konsep hegemoni Barat kepada Timur dari 
Said, kemudian dilanjutkan oleh (Bhabha, 1994) yang mengeksplorasi superioritas bangsa Barat yang mendorong bangsa Timur untuk meniru (mimikri) dan menyesuaikan diri mereka engan wujud Barat yang lebih superior (Bhabha, 1994; Galvan-Alvarez et al., 2020).

Efek berantai dari penjajahan dan hegemoni memunculkan pertanyaan tentang jati diri dan kepribadian yang otentik dari bangsa terjajah (Darby, 2018). Pertanyaan tersebut muncul karena bangsa Timur dianggap "temuan" dari bangsa Barat (do Mar Castro Varela \& Tamayo Rojas, 2020; Said, 2010). Dari pertanyaan tersebut, kemudian memunculkan karya-karya yang menyelidiki tema-tema terkait relasi bangsa penjajah dan bangsa terjajah. Penelitian yang membahas situasi bangsa terjajah di Afrika (Shanguhyia \& Falola, 2018); Australia, Kanada, Kepulauan Karibia, Irlandia, Amerika Latin (McLeod, 2007); Perancis, Inggris, Amerika (McLeod, 2007; Young, 2003). Sudut pandang yang sudah dibahas berkisar pada kebudayaan (McLeod, 2007; Rangan \& Chow, 2013), analisis psikologi (McLeod, 2007), identitas (Huddart, 2007), politik, rasisme, dan feminisme (Rutazibwa \& Shilliam, 2012). Beberapa tema itu juga dilengkapi dengan analisis spesifik tentang stereotip, mimikri, ambivalensi, dan hibriditas (Bhabha, 1994); subalternity dan orientalisme (Said, 2010).

Hegemoni yang sama ternyata juga ditemukan di dalam diri bangsa Indonesia, sebagaimana diungkapkan oleh Soekarno bahwa "masyarakat kita (Indonesia) menjadi masyarakat kecil, tidak percaya diri, dan selalu ingin dituntun" (Soekarno, 1964a: 257) dan "bangsa kulit berwarna itu memang bangsa yang kurang dan bangsa kulit putih itu adalah adhiadhining bangsa. Injeksi inlander bodoh, kerbau, dll selalu dilakukan oleh kolonial" (Soekarno, n.d: 114). Merujuk ungkapan Soekarno tersebut menunjukan bahwa hegemoni dari kolonial telah menyebabkan terkonstruksinya pemikiran bangsa Indonesia sehingga merasa inferior dan menganggap kolonial lebih superior. Hal lain yang potensial menjadi masalah dari penjajahan dan hegemoni yang harus dialami oleh bangsa terjajah seperti Indonesia adalah meleburnya atau hilangnya identitas, jati diri dan kepribadiannya bangsa (Bhabha, 1994; Huddart, 2006).

Salah satu upaya yang dilakukan oleh para founding person bangsa untuk menemukan identitas jati diri bangsa Indonesia setelah sekian lama mengalami penjajahan adalah melalui pidato 1 Juni 1945 yang disampaikan oleh Soekarno(Latif, 2018b). Dalam pidato 1 Juni 1945, Soekarno menggali konsep fundamental berupa jati diri dan kepribdadian bangsa yang menyerap semua elemen di dalamnya (Latif, 2018a). Memang secara eksplisit Soekarno tidak menyebut kata "kepribadian" atau "jati diri". Namun hal ini secara implisit dapat dilihat ketika Soekarno menggunakan istilah philosofischegrondslag dan weltanschauung sebagai berikut: "Philosofischegrondslag dari pada Indonesia merdeka. Philosofischegrondslag itulah pundamen, filsafat, pikiran yang sedalamdalamnya, jiwa, hasrat yang sedalamdalamnya untuk di atasnya didirikan gedung Indonesia Merdeka yang kekal dan abadi. [...] bahwa kita harus mencari persetujuan, mencari persetujuan faham. Kita bersama-sama mencari persatuan philosophischegrondslag, mencari satu "Weltanschauung" yang kita semua setuju. Saya katakan lagi setuju! Yang saudara Yamin setujui, yang Ki Bagoes setujui, yang Ki Hajar setujui, yang sdr. Sanoesi setujui, yang sdr. Abikoesno setujui, yang sdr. Lim Koen Hian setujui, pendeknya kita semua mencari satu modus" (Soekarno, 1964a).

Untuk menggali jati diri bangsa, Soekarno tidak mempraktikkan pola komunikasi yang monologis, satu arah, dan canonical yang khas digunakan dalam membentuk identitas bangsa (Bhabha, 1990). Pola komunikasi semacam itu tidak akan berhasil sebab kekayaan nilai yang ada di Indonesia tidak akan mungkin disempitkan dalam satu pola saja (Pawito et al., 2020). Corak komunikasi Soekarno pun bukan sekedar mencari kompromi, tapi mencari 
persetujuan bersama atas setiap perbedaan atau biasa disebut oleh Habermas (1987) sebagai konsensus. Sebagaimana tercermin dalam pernyataan Soekarno sebagai berikut "...bahwa kita harus mencari persetujuan, mencari persetujuan faham. Kita bersama-sama mencari persatuan philosophische grondslag, mencari satu Weltanschauung yang kita semua setuju" (Soekarno, 1964b:17). Dengan corak komunikasi yang berusaha menumbuhkan konsensus, Soekarno berusaha membangun identitas jati diri bangsa Indonesia, salah satunya melalui pidato 1 Juni 1945 yang pada akhirmya menjadi "akar" lahirnya Pancasila sebagai dasar negara Indonesia (Latif, 2018a; 2018b).

Berangkat dari perspektif pascakolonialisme, penulis melihat bahwa Indonesia memiliki momen komunikasi yang khas untuk menggali jati diri dan kepribadian bangsa, yakni pidato 1 Juni 1945 oleh Soekarno. Penulis tertarik melakukan penelitian terhadap pidato 1 Juni 1945 oleh Soekarno untuk mengetahui identitas jati diri bangsa Indonesia sebagai bangsa yang pernah dijajah. Sebelumnya telah ada beberapa kajian terkait pidato 1 Juni 1945 dan (atau) Pancasila yang sudah pernah dilakukan, kajian tersebut berkisar pada diskursus Pancasila dalam ormas keagamaan (Romadlan, 2020); multikulturalisme (Dewantara, 2015); komunikasi politik (Jaya, 2016); hermeneutika dan Pancasila (Pamungkas, 2018); kritik ideologi (Seran, 2015), pendidikan (Siswoyo, 2013b, 2013a), dan pluralisme (Syahputra, 2015). Dari studi-studi yang ada, penulis belum menemukan satu studi tinjauan khusus yang mengangkat atau pun membahas pidato 1 Juni 1945 dari sudut pandang third space of communication untuk menemukan identitas bangsa Indonesia sebagai korban penjajahan.

Penulis memutuskan untuk mengisi gap research dengan membahas pidato 1 Juni 1945 yang dilakukan oleh Soekarno dari sudut pembentukan ruang komunikasi bersama untuk menemukan identitas bangsa Indonesia. Penulis menggunakan third space of communication sebagai kerangka berpikir untuk melihat usaha Soekarno pada pidato 1 Juni 1945 dalam menemukan jati diri dan kepribadian bangsa dan untuk melawan hegemoni penjajah. Bhabha (1994) menggunakan third space of communication untuk membuktikan bahwa tidak ada kebudayaan yang kaku(fixed), kebudayaan itu dinamis dan selalu memengaruhi satu sama lain. Di sisi lain, third space of communication juga dapat dijadikan instrumen untuk mempersatukan sebuah kelompok masyarakat yang memiliki latar belakang yang berbeda (Widdowson, 2007).

Ada beberapa alasan penulis menggunakan konsep third space of communication. Pertama, konsep third space of communication berangkat dari kajian pascakolonialisme (Cook \& Wei, 2009: 236) yang berarti memunculkan kesamaan latar belakang antara lahirnya konsep ini dengan situasi Indonesia yang pernah dijajah oleh Barat. Kedua, konsep third space of communicaiton memiliki karakter perlawanan terhadap hegemoni penjajah (Rutherford, 1990) dan menjadi pertanda terbentuknya nilai-nilai baru yang diterima entitas atau latar belakang yang berbeda (Bhabha, 1994) seperti karakteristik bangsa Indonesa yang multikultural. Ketiga, konsep third space of communication memberi kesempatan bagi mereka yang terpinggirkan untuk mendapat tempat utama. Hal ini sejalan dengan kondisi Indonesia saat penjajahan, yang mana pada saat itu ada nilai-nilai yang terpinggirkan (Mahfud, 2020). Konsep third space of communication (Bhabha, 1994) digunakan oleh penulis untuk menjelaskan bagaimana usaha Soekarno melalui pidato 1 Juni 1945 dalam membentuk ruang komunikasi bersama untuk menemukan identitas, jati diri, dan kepribadian bangsa Indonesia yang sempat terkubur karena hegemoni penjajahan. 
Tabel 1. Daftar Sumber Data Penelitian (Teks-Teks Asli)

\begin{tabular}{ccc}
\hline No & Dokumen & Tahun \\
\hline 1 & Transkrip Pidato 1945 & 1945 \\
2 & Buku "Tjamkan Pantjasila" & 1964 \\
3 & Buku "Di Bawah Bendera & 1964 \\
& Revolusi" & \\
4 & Buku "Indonesia Menggugat" & (n.d.)
\end{tabular}

Sumber: Koleksi pribadi peneliti (2020)

\section{Metode Penelitian}

Secara implisit, pembangunan third space of communication dapat dilihat dari pernyataan Soekarno yang menyebut nilai-nilai asli Indonesia yakni ketuhanan, musyawarahmufakat, demokrasi ekonomi, internasionalisme, dan gotong royong (Soekarno, 1946a; 1946b). Nilai-nilai tersebut bukan nilai warisan penjajah, melainkan nilai-nilai yang menjadi pemikiran Soekarno sebagai salah satu di antara founding persons bangsa Indonesia. Nilai-nilai tersebut tidak bisa dianalisis jika hanya melihat pidato 1 Juni 1945 saja. Diperlukan telaah lebih jauh dengan menganalisis tulisan-tulisan, pemikiran, dan konteks hidup Soekarno. Maka metode yang digunakan dalam penelitian ini adalah "lingkar hermeneutika" dari Gadamer (2004).

Lingkar hermeneutika Gadamer tidak melihat pidato 1 Juni 1945 sebagai susunan huruf, kata, dan paragraf saja. Studi hermeneutika meyakini bahwa dalam kata dan bahasa ada klaim tentang "cara mengada" yakni sebuah teks pasti tersusun atas banyak gagasan dan dituliskan dalam satu konteks waktu tertentu (Gadamer, 2004), dalam hal ini adalah kondisi sosial, budaya, politik ketika Soekarno menyusun teks pidato 1 Juni 1945.

Gadamer (2004) memandang teks (bahasa) sebagai house of being. Dalam hal ini, sebuah teks tidaklah jatuh dari langit, artinya teks dituliskan dalam satu rentang waktu dan konteks zama tertentu. Oleh karena itu, untuk memahami teks secara komprehensif, diperlukan juga pemahaman atas pemikiran pencetus teks (Gadamer, 2004). Dengan kata lain, untuk mendapatkan makna terdalam dari pidato 1 Juni 1945, peneliti juga akan menganalisis sosok Soekarno sebagai being - supaya dapat mengerti seluk-beluk pemikiran Soekarno dalam membangun identitas bangsa Indonesia yang terbelenggu oleh hegemoni penjajahan.

Penelitian ini menganalisis pidato tokoh Soekarno sebagai salah satu founding persons yang menggagas identitas bangsa Indonesia, dan adapun objek utama penelitian ini adalah pidato 1 Juni 1945 sebagai wadah Soekarno menuangkan gagasannya mengenai identitas bangsa Indonesia. Penelitian ini menggunakan teknik penggalian data dokumentasi yakni transkrip teks pidato 1 Juni 1945. Kemudian, mengingat penelitian ini adalah studi hermeneutika, maka teknik penggalian data dilengkapi tulisan-tulisan asli Soekarno yang tersebar di beberapa buku. Sumber data dalam penelitian ini dilihat pada Tabel 1 .

Sumber data yang digunakan Tabel 1 adalah teks-teks asli yang mengantarkan peneliti kepada lived reality dari objek yang diteliti (Liberman, 2016). Sesuai dengan langkah hermeneutika Gadamer, maka teks pidato 1 Juni 1945 menyinggung parts and whole. Unsurunsur dari teks (parts) tidak bisa dipahami tanpa memahami kebudayaan dan latar belakang pencetus teks (whole) (Palmer, 1969). Artinya, sebuah makna dari satu teks hanya dipahami ketika penafsir juga memahami konteks zaman dan kebudayaan pencetus teks (Jensen, 2018).

Teknik analisis data dalam penelitian ini menggunakan lingkar hermeneutika Gadamer (2004) yang melibatkan tafsir peneliti. Tafsif tersebut antara lain: Pertama, pra-anggapan dari peneliti (horizon penafsir), yakni penafsir atau peneliti mengontekstualisasikan antara teks-konteks dalam kondisi sosiohistoris. Pra anggapan menjadi pemahaman yang produktif dan bukanlah suatu penghalang untuk mencapai pemahaman yang komprehensif; Kedua, syarat untuk mencapai pemahaman yang komprehensif adalah fusion of horizon yakni penafsir atau peneliti wajib mengintegrasikan makna yang 
ditemukannya ke dalam teks sebagai bentuk historically effected consciousness, membuat penafsir atau peneliti sadar tentang keberlanjutan historis atas suatu makna (Mueller-Vollmer, 1987; Winartono, Antoni, \& Sujoko, 2019).

Dengan skema metodologis yang sedemikan, penelitian ini mampu menjelaskan secara komprehensif berkaitan dengan third space of communication Soekarno dalam Pidato 1 Juni 1945 untuk menemukan identitas, jati diri, dan kepribadian bangsa Indonesia yang sempat terkubur karena hegemoni pada masa kolonialisme. Penelitian ini dapat memberikan kontribusi terhadap kajian keilmuan komunikasi kepribadian bangsa secara umum, dan kajian pascakolonilisme secara khusus.

\section{Hasil Penelitian dan Pembahasan \\ Nilai Persatuan dalam ThirdSpaceofCommunication Pidato 1 Juni 1945}

Bagian awal pidato 1 Juni 1945, Soekarno menyebut dua istilah krusial, yakni philosophischegrondslag (dasar filosofis) dan Weltanschauung (pandangan dunia). Menurut Soekarno itulah jiwa, kepribadian, dan landasan yang "....di atasnya akan didirikan gedung Indonesia Merdeka yang kekal abadi” (Soekarno, 1964b: 33). Dua istilah tersebut muncul beberapa kali dalam bagian awal pidato, namun perubahan terjadi menjelang penyebutan prinsip pertama. Ketika itu, Soekarno menambahkan kata "persatuan" sebagai berikut:

"Kita bersama-sama mencari persatuan philosophischegrondslag, mencari satu "Weltanschauung yang kita semua setuju. Saya katakan lagi setuju! Yang saudara Yamin setujui, yang Ki Bagoes setujui, yang Ki Hajar setujui, yang sdr. Sanoesi setujui, yang sdr. Abikoesno setujui, yang sdr. Lim Koen Hian setujui, pendeknya kita semua mencari satu modus" (Soekarno, 1964b:18)

Tambahan kata persatuan tersebut menyiratkan pesan bahwa pada mulanya Indonesia memiliki beberapa pandangan dasar dalam berbangsa, hal tersebut bisa dirunut dan dapat dibuktikan melalui tulisan Soekarno semasa muda, yakni Nasionalisme, Islamisme, dan Marxisme (1926), Kearah Persatuan (1928), dan Saja Kurang Dinamis (1940). Soekarno terlihat ingin memakai "persatuan" sebagai salah satu nilai yang meski diperjuangkan dan menjadi identitas bangsa (Soekarno, 1964a). Soekarno ingin membangun nilai persatuan dalam third space of communication melalui pidato 1 Juni 1945 sebagai salah satu identitas atau pun nilai bersama bangsa Indonesia. Hal yang sama juga muncul dalam pidato 1 Juni 1945, Soekarno kembali mengajak mencari persatuan, namun terdapat perbedaan yakni Soekarno menambahkan unsur "kita" di dalam pidato 1 Juni 1945. Hal tersebut menunjukan ide tentang "persatuan" tidak lagi muncul dari kepala Soekarno 'sendiri', sebaliknya Soekarno mengajak peserta sidang BPUPKI untuk bersama-sama melalui diksi 'kita' dalam berpikir tentang fundamen dasar bagi bangsa Indonesia (Soekarno, 1946b). Ajakan Soekarno melalui diksi "kita" kepada para perserta sidang BPUPKI merupakan cara membangun kesepahaman bersama atau konsensus tentang nilai fundamen dasar bangsa Indonesia.

Perbedaan mencolok pidato 1 Juni 1945 dengan artikel-artikel tadi adalah ajakan Soekarno kepada peserta sidang untuk berpikir bersama-sama dan mecari satu modus sebagai nilai dasar bangsa Indonesia. Makna persatuan tidak lagi dipaksakan oleh Soekarno -seorang-, melainkan melibatkan berbagai elemen atau ide dari para founding persons lainnya yang terlibat dalam sidang BPUPKI. Terlihat bahwa Soekarno menyebut nama-nama pribadi yang menyimbolkan latar belakang suku, agama, ras dan kebudayaan yang berbeda: “...Yang saudara Yamin setujui, yang Ki Bagoes setujui, yang Ki Hajar setujui, yang sdr. Sanoesi setujui, yang sdr. Abikoesno setujui, yang sdr. Lim Koen Hian setujui, pendeknya kita semua mencari satu modus" (Soekarno, 1964b:18). Dalam hal ini, Soekarno ingin membangun persetujuan bersama di antara para founding persons 
yang memiliki latar belakang berbeda untuk mendapatkan dasar bangsa Indonesia, yakni dengan cara memunculkan ruang komunikasi bersama untuk mencapai konsensus -disebut dalam satu modus. Alhasil, upaya Soekarno dalam membangun ruang komunikasi bersama untuk menemukan konsensus dasar bangsa Indonesia juga tercermin dalam kutipan berikut:

"Tuan Yamin, ini bukan compromis, tetapi kita bersama-sama mencari satu hal yang kita ber-sama-sama setujui... Baik saudara-saudara yang bernama kaum kebangsaan yang disini, maupun saudarasaudara yang dinamakan kaum Islam, semuanya telah mufakat, bahwa bukan yang demikian itulah kita punya tujuan. Kita hendak mendirikan suatu negara 'semua buat semua'." (Soekarno, 1964b: 18)

Kemampuan Soekarno membangun ruang komunikasi bersama untuk mendapatkan konsensus dasar bangsa Indonesia menjadi sebuah transformasi di dalam dirinya di mana dalam beberapa tulisan-tulisan yang ada menunjukan bahwa Soekarno sebagai personal yang selalu berusaha sendiri untuk membuat sintesis atas berbagai nilai, ide, atau pun gagasan. Sebagaimana hal tersebut tercermin dalam ungkapan Soekarno sebagai berikut "...secara politis, Soekarno nasionalis. Secara agama, Bung Karno beragama. Secara ideologi, Bung Karno Sosialis. Saya berkepala 3" (Adams, 1965:75). Unsur kedirian itu tidak lagi tercermin di dalam pidato 1 Juni 1945. Alih-alih menonjolkan dirinya sebagai pembuat sintesis (tunggal), di dalam pidato 1 Juni 1945, Soekarno meleburkan pemikirannya bersama peserta sidang yang lain. Hal tersebut menunjukan dengan jelas bahwa Soekarno memberikan unsur kebersamaan dalam membangun ruang komunikasi untuk menemukan dasar bangsa Indonesia.

Ide persatuan juga dapat dilihat ketika Soekarno mengajukan prinsip permusyawaratan perwakilan (Soekarno, 1964b). Alih-alih mengulangi tendensi kedirian, Soekarno memilih untuk membuat semua nilai itu sama di hadapan Badan Perwakilan Rakyat. Badan itulah yang menjadi tempat diskusi dan medan perjuangan nilai bagi rakyat Indonesia. Di dalamnya, semua pihak adalah setara dan mendapatkan kesempatan untuk memperjuangkan nilai-nilai yang diyakini (Soekarno, 1964b). Soekarno memiliki ciri khas yakni sikap demokratis dalam membangun third space of communication untuk menemukan dasar bangsa Indonesia. Sebagaimana hal tersebut juga tercermin dalam pernyataan Soekarno sebagai berikut: "Dan hati Islam Bung karno ini, ingin membela Islam dalam mufakat, dalam permusyawaratan. Dengan cara mufakat, kita perbaiki segala hal, juga keselamatan agama, yaitu dengan jalan pembicaraan atau permusyawaratan di dalam Badan Perwakilan Rakyat. Apa-apa yang belum memuaskan, kita bicarakan di dalam permusyawaratan. Badan perwakilan, inilah tempat kita untuk mengemukakan tuntutantuntutan Islam. Disinilah kita usulkan kepada pemimpin-pemimpin rakyat, apa-apa yang kita rasa perlu bagi perbaikan" (Soekarno 1964b: 8)

Berdasarkan kutipan tersebut dimunculkan tafsir horizon (Gadamer, 2004) dari penulis yakni gagasan musyawarah-mufakat merupakan perkembangan gagasan-gagasan Soekarno muda: dari 'persatuan yang dipaksakan' menjadi 'fasilitator persatuan'. Embrio atau cikal-bakal 'fasilitator persatuan' tersebut dapat dilihat di artikel Indonesia vs Fasisme (1940) dan menjadi matang dalam pidato 1 Juni 1945. Dalam hal ini, Soekarno mengetahui benar bahwa Indonesia merupakan bangsa yang beragam dan jiwa rakyat Indonesia adalah kerakyatan. Hal tersebutlah yang disebut Soekarno dengan "erat dengan adat, rapat-rapat dan mufakat" (Soekarno, 1964b). Dalam penentuan nilai persatuan, penulis melihat bahwa Soekarno ingin menjadi pengendali atau penentu ide persatuan, tetapi Soekarno juga bukanlah menjadi aktor tunggal penentu ide persatuan. Seiring berjalannya waktu, Soekarno lebih menekankan pada proses musyawarah-mufakat; proses yang menjadi identitas bangsa Indonesia. Sebagaimana tercermin seperti kutipan berikut: 
"Dalam perwakilan nanti ada perjoangan sehebat-hebatnya. Tidak ada satu staat yang hidup betul-betul hidup, jikalau di dalam badan-perwakilannya tidak seakan-akan bergolak mendidih kawah Candradimuka, kalau tidak ada perjoangan faham di dalamnya. Baik di dalam staat Islam, maupun di dalam staat Kristen, perjoangan selamanya ada" (Soekarno, 1964b: 26). Hasil analisis hermeunetika juga ditemukan bahwa ide persatuan dari Soekarno merupakan perpaduan gagasan dari Ernest Renan, Otto Bauer dan konsep geopolitik dari dirinya sendiri - hal ini sekaligus membuktikan bahwa salah satu ciri khas Soekarno yang tak mampu hilang, yakni melakukan sintetis dari berbagai pemikiran dan memodifikasinya. Dari gagasan Renan, Soekarno tahu bahwa bangsa adalah sekelompok manusia yang mau bersatu, yang merasa dirinya bersatu (Soekarno, 1964b). Renan percaya bahwa bangsa itu adalah spiritual family (Renan dalam Bhabha, 1990); dan itu terbentuk dari kebutuhan sekelompok orang yang menginginkan identitas kolektif demi sebuah perjuangan. Gagasan dari Renan inilah yang diambil oleh Soekarno untuk menjadi nilai yang dapat diperjuangkan sebagai identitas bangsa Indonesia setelah mengalami kolonialisme dari Barat.

Dari Otto Bauer, Soekarno tahu bahwa bangsa adalah persatuan perangai yang timbul karena persamaan nasib. Soekarno sengaja mengutip pendapat Bauer karena sesuai dengan kondisi bangsa Indonesia yang saat itu sedang ada dalam nasib yang sama, yakni penderitaan akibat penjajahan (Soekarno, 1964b). Kedua pendapat ini dinilai tidak cukup karena melupakan satu kondisi faktual bangsa Indonesia, yakni keberadaan berbagai macam suku, ras, dan kebudayaan yang tersebar di berbagai wilayah geografis Indonesia. Untuk itulah Soekarno menawarkan konsep geopolitik. Untuk konsep geopolitik ini, Soekarno berkata: "Kemarin, kalau tidak salah, saudara Ki Bagoes Hadikoesoemo, atau Moenandar, mengatakan tentang "Persatuan antara orang dan tempat". Persatuan antara orang dan tempat, tuan-tuan sekalian, persatuan antara manusia dan tempatnya! Orang dan tempat tidak dapat dipisahkan! Tidak dapat dipisahkan rakyat dari bumi yang ada di bawah kakinya. Ernest Renan dan Otto Bauer hanya sekedar melihat orangnya. Mereka hanya memikirkan "Gemeinschaft"nya dan perasaan orangnya, "l'ame et desir". Mereka hanya mengingat karakter, tidak mengingat tempat, tidak mengingat bumi, bumi yang didiami manusia itu" (Soekarno, 1964b: 20) Dari sudut third space of communication, apa yang dilakukan oleh Soekarno merupakan usaha untuk meredam fanatisme kebudayaan yang dapat berujung pada gerakan separatis. Dalam hal ini, Soekarno ingin membangun kebangsaan yang lebih luas, bukan sekedar persatuan yang berdasarkan persamaan nasib, tapi juga mempersatuan keberadaan berbagai macam suku, ras, dan kebudayaan yang ada di Indonesia. Apabila hanya bertumpu pada gagasan Renan dan Bauer yang berfokus pada manusianya, maka yang terjadi ialah mereka potensial bisa melepaskan diri dari persatuan bangsa oleh karena itu Soekarno melenggkapi dengan gagasan geopolitiknya untuk menjadikan Indonesia sebagai kesatuan yang utuh. Sebagaimana hal tersebut tercermin pada ungkapan berikut: "Maaf saudara-saudara, saya mengambil contoh Minangkabau, diantara bangsa di Indonesia, yang paling ada "desir d'entre ensemble”, adalah rakyat Minangkabau, yang banyaknya kira-kira 2,5 milyun. Rakyat ini merasa dirinya satu keluarga. Tetapi Minangkabau bukan satu kesatuaan, melainkan hanya satu bahagian kecil dari pada satu kesatuan! Penduduk Yogyapun adalah merasa "le desir d"etre ensemble", tetapi Yogyapun hanya satu bahagian kecil dari pada satu kesatuan. Di Jawa Barat rakyat Pasundan sangat merasakan "le desir d'etre ensemble", tetapi Sundapun hanya satu bahagian kecil dari pada satu kesatuan" (Soekarno, 1964b:21). Berdasar data tersebut, Soekarno tidak hanya menyinggung tentang persatuan berdasarkan keinginan internal kelompok atau individu (kehendak dan nasib). Dengan menyinggung geopolitik, Soekarno ingin 
membangun persatuan yang didasarkan pada kondisi faktual Indonesia yang memiliki beragam latar belakang. Soekarno hendak menyadarkan bangsa Indonesia bahwa setiap daerah, suku, dan kebudayaan adalah anggota dari kesatuan yang lebih besar, yakni Indonesia. Jadi dalam nilai persatuan, Soekarno berusaha menjadikan Indonesia sebagai wadah besar yang menampung semua golongan tanpa terkecuali.

\section{Nilai Keberagaman dalam Third Space} of Communication Pidato 1 Juni 1945

Sifat utama dari third space of communication adalah mempersatukan nilai-nilai yang berbeda dan pada akhirnya menghasilkan satu nilai baru (Rutherford, 1990). Setiap nilai yang berbeda itu saling memengaruhi dan diterjemahkan secara baru (Bhabha, 1994). Hal inilah yang dilakukan Soekarno untuk membentuk salah satu identitas bangsa Indonesia melalui pidato 1 Juni 1945. Nilai persatuan yang sebelumnya telah dijelaskan bukanlah entitas tunggal, artinya persatuan bukan dalam rangka menyeragamkan perbedaan, tetapi karena adanya perbedaan maka dibutuhkan persatuan untuk membentuk sebuah bangsa yakni Indonesia. Jadi, dalam hal ini sebenarnya nilai keberagaman diusung oleh Soekarno sebagai pijakan persatuan bangsa Indonesia.

Usaha untuk mempersatukan keragaman beberapa kali disinggung oleh Soekarno, misalnya dalam prinsip kebangsaan, persatuan yang diinginkan oleh Soekarno adalah persatuan berlandaskan nasionalisme, bukan persatuan etnis. Hal yang sama juga ditemukan ketika Soekarno membahas prinsip ketiga, yakni persatuan. Soekarno menegaskan pentingnya kesatuan yang harus berdiri di atas banyaknya kepentingan golongan, sebagaimana ungkapan berikut "[...] Negara Indonesia bukan satu negara untuk satu orang, bukan satu negara untuk satu golongan, walaupun golongan kaya. Tetapi kita mendirikan negara "semua buat semua", "satu buat semua, semua buat satu" (Soekarno, 1964b: 25). Merujuk juga pada ungkapan Soekarno seperti berikut:
"Maaf saudara-saudara, saya mengambil contoh Minangkabau, diantara bangsa di Indonesia, yang paling ada "desir d'etre ensemble", adalah rakyat Minangkabau, yang banyaknya kira-kira 2,5 milyun. Rakyat ini merasa dirinya satu keluarga. Tetapi Minangkabau bukan satu kesatuaan, melainkan hanya satu bahagian kecil dari pada satu kesatuan! Penduduk Yogya pun adalah merasa "le desir d'etre ensemble", tetapi Yogyapun hanya satu bahagian kecil dari pada satu kesatuan. Di Jawa Barat rakyat Pasundan sangat merasakan "le desir d'etre ensemble", tetapi Sunda pun hanya satu bahagian kecil dari pada satu kesatuan" (Soekarno, 1964b:25) Gagasan nilai keberagaman sebagai pijakan persatuan dari Soekarno tidak muncul begitu saja dalam Pidato 1 Juni 1945, begitu juga nilai keberagaman yang tidak hanya berdasarkan suku, etnis, dan wilayah - melainkan juga keberagaman ideologis yang berusaha dijadikannya kesatuan. Hal tersebut ditunjukan dari rintisan ide yang telah ada dalam Soekarno muda, setidaknya sejak tahu 1926 ketika ia menulis artikel Nasionalisme, Islamisme, dan Marxisme. Artikel tersebut merupakan usaha Soekarno untuk membangun persatuan nasional berdasarkan ideologis yang beragam (Latif, 2018b) dan sebagai sarana pembuktian bahwa ketiga sifat itu tidak bertentangan satu sama lain. Penulis melihat bahwa usaha Soekarno ini merupakan aplikasi nyata dari third space of communication - Soekarno mengajak bangsa Indonesia untuk memiliki common agreement yang dicapai dengan negosiasi makna, dan mereformulasinya lewat istilah yang berbeda (Widdowson, 2004).

Upaya yang dilakukan Soekarno di tahun 1926, membuat kesatuan dari tiga ideologis tersebut masih berlanjut hingga pidato 1 Juni 1945. Hal ini ditandai dengan penyebutan prinsip gotong-royong yang merupakan kamuflase dari gagasan keberagaman yang menjadi pijakan nilai persatuan yang memang dieluh-eluhkan oleh Soekarno. Gagasan keberagaman inilah yang melahirkan prinsip gotong-royong yang tidak hanya menjadi simbol identitas, tetapi 
juga menjadi simbol persatuan. Sebagaimana diungkapkan Seokarna seperti berikut: “[...] gotong royong adalah faham yang dinamis, lebih dinamis dari 'kekeluargaan', saudarasaudara! Kekeluargaan adalah satu faham yang statis, tetapi gotong-royong menggambarkan satu usaha, satu amal, satu pekerjaan, yang dinamakan anggota yang terhormat Soekardjo satu karyo, satu gawe." (Soekarno, 1964b: 32).

Keinginan yang besar dalam diri Soekarno untuk mempersatukan segenap elemen yang berbeda sempat menjadikan dirinya sebagai orang yang "mabuk persatuan" dan "mabuk akan perdamaian" (Adams, 1965). Hal ini tidak lepas dari fakta bahwa Soekarno selalu ingin mengusahakan persatuan, entah bagaimana pun caranya. Dimulai dengan mencari persamaanpersamaan di antara nilai-nilai yang berbeda, menjadikan pihak kolonial menjadi musuh bersama, dan menggunakan wacana kemiskinan agar rakyat mau melancarkan revolusi yang radikal. Keinginan yang besar tersebut tidak bisa dilepaskandarimasamudaSoekarno,dimanasejak muda, Soekarno telah melihat praktik penjajahan yang identik dengan politik diskriminasi yang memisahkan masyarakat Indonesia berdasarkan etnis dan latar belakang. Sebagaimana hal tersebut tercermin dalam kutipan berikut:

"One of Sukarno's miracles is that he united his people. The color of our skin may differ, the shape of our noses and foreheads may differ: Irians are black, Sumatrans brown, Javanese are short, inhabi- tants of the Moluccas taller, people from Lampung have their own features, those from Pasundan have their own features, but no more are we islanders and strangers. Today we are Indonesians and we are one. Our country's motto is Bhirmeka Tunggal Ika-"Unity in Diversity." Adams, 1965, hal. 20).

Guna membentuk rasa persatuan paham di antara keberagaman yang ada, Soekarno tidak lagi melanjutkan politik diskriminasi yang dilakukan pemerintahkolonial. Soekarmopuntidak condong kepada etnis, kebudayaan dan agama mayoritas untuk menyatukan Indonesia (Hargens, 2019), tetapi Soekarno condong dengan nasionalisme Indonesia. Soekarno membiarkan keragaman tetap menjadi identitas Indonesia, karena realitas kemajemukan diyakini sebagai proses menuju kesadaran yang mengandaikan adanya kerelaan tiap orang agar membayangkan diri sebagai satu identitas bernama "bangsa" (Anderson, 2006).

Usaha mencapai paham persatuan tersebut, terlihat dalam pidato 1 Juni 1945 dari Soekarno yang menyinggung (baik secara implisit maupun eksplisit) hampir semua unsur kemajemukan. Agama (Kristen, Islam, Hindu, Buddha), latar belakang etnis (Minang, Jawa, Yogya) dan aliran politik (sosialisme dan kapitalisme) tanpa ada tendensi untuk memecah belah. Hal itu dirangkum dengan menyebut prinsip gotongroyong yang identik dengan kekeluargaan, usaha dan perjuangan bersama. Pada intinya, gagasan Soekarno tentang persatuan Indonesia bukan menjadikan keberagaman menjadi seragam atau sama, tetapi mengonsepsikan keberagaman meski melahirkan persatuan demi terbentuknya Negara Kesatuan Republik Indonesia.

Keberagaman telah menjadi sesuatu yang niscaya dalam diri bangsa Indonesia. Mempersatukan keberagaman itu adalah tugas yang cukup berat, mengingat politik diskriminasi warisan dari bangsa penjajah sudah mendominasi di Indonesia. Usaha untuk membangun persatuan nasional itu adalah konsepsi yang melampaui emosi dan pikiran (Hargens, 2019). Nasionalisme seharusnya menyentuh aspek mutu hidup sebuah bangsa untuk memperoleh makna esensial yang mampu menggerakkan perubahan nyata bagi perbaikan kualitas kemanusiaan secara individual maupun kolektif sebagai komunitas pikiran (Hargens, 2019). Dalam pidato 1 Juni 1945, usaha perbaikan kualitas kemanusiaan itu ada pada ajakan untuk merdeka, karena kemerdekaan adalah suatu jembatan emas. Sebagaimana hal tersebut diungkapkan oleh Soekarno "[...] di seberang jembatan emas itu, kita leluasa menyusun masyarakat Indonesia merdeka yang gagah, kuat, 
sehat, kekal dan abadi" (Soekarno, 1964b: 15). Dalam hal ini, Soekarno yang mengonsepsikan kemerdekaan sebagai suatu jembatan emas untuk mengantarkan Indonesia sebagai negara yang gagah, kuat, kekal, dan abadi setelah terlepas dari belenggu penjajagan kolonial.

\section{Nilai Martabat Indonesia dalam Third} Space of Communication Pidato 1 Juni 1945

Wujud third space of communication yang berikutanya terlihat ketika Soekarno mewacanakan martabat Indonesia di hadapan bangsa asing melalui prinsip internasionalisme. Prinsip tersebut dilihat oleh Soekarno sebagai sarana agar masyarakat Indonesia tidak menjadi bangsa yang chauvinistis - bangsa yang "buta" terhadap budaya asing dan fanatik terhadap budayanya sendiri. Sebagaimana ungkapan Soekarno berikut, "Tuan-tuan, jangan berkata, bahwa bangsa Indonesialah yang terbagus dan termulya, serta meremehkan bangsa lain. Kita harus menuju persatuan dunia, persaudaraan dunia" (Soekarno, 1964b: 24). Dengan demikian, penulis menafsirkan apa yang ditawarkan oleh Soekarno adalah pengangkatan martabat bangsa Indonesia yang pernah terjajah di hadapan bangsa asing lebih sublimatis yakni mengangkat martabat bangsa Indonesia, tanpa merendahkan martabat bangsa lain melalui prinsip internasionalisme.

Keberanian memunculkan prinsip internasionalisme, merupakan usaha Soekarno dalam mengangkat derajat bangsa Indonesia sehingga berdiri sejajar dengan bangsa-bangsa lain. Soekarno membahasakan hal tersebut secara lebih diplomatis dan positif dengan ungkapan "[...] kita harus menuju persatuan dunia, persaudaraan dunia. Kita bukan saja harus mendirikan negara Indonesia Merdeka, tetapi kita harus menuju pula kepada kekeluargaan bangsabangsa. Justru inilah prinsip saya yang kedua. Inilah filosofisch principe yang nomor dua, yang saya usulkan kepada Tuan-tuan, yang boleh saya namakan "internasionalime" (Soekarno, 1964b: 24). Jadi dalam hal ini, Soekarno berusaha menghapuskan historisitas dari penjajahan tentang Timur yang terjajah sebagai bangsa inferior, dan tentang Barat yang menjajah sebagai bangsa superior (Bhaba, 1990; Said, 2010).

Pengangkatan derajat bangsa Indonesia yang dilakukan oleh Soekarno juga menjadi penanda bahwa ada usaha untuk mematahkan pola komunikasi stereotip yang sudah dibangun oleh bangsa Barat, yakni stereotip bangsa inferiorsuperior (Bhaba, 1990). Sekat inferior-superior juga dikaburkan ketika Soekarno berani untuk mengritik praktik demokrasi Barat (Yunaldi, 2020). Soekarno menganggap demokrasi Barat sebagai sistem pemerintahan yang tidak akan mampu memberikan kesejahteraan bangsa Indonesia, karena karakteristik bangsa Barat yang berbeda dengan bangsa Indonesia. Perbedaan yang dimaksud bukan pada perbedaan bangsa yang lebih superior atau bangsa yang inferior dalam menjalakan demokrasi, melainkan perbedaan pada karakteristik sosiologis atau socio-democratie (Soekarno, 1946b). Sebagaimana hal tersebut tercermin dari ungkapan Soekarno seperti berikut: "[...] dan demokrasi yang bukan demokrasi barat, tetapi politiek- economische demokratie, yaitu politieke demokrasi dengan sociale rechtvaardigheid, demokrasi dengan kesejahteraan, saya peraskan pula menjadi satu: Inilah yang dulu saya namakan socio-democratie." (Adams, 1965, hal. 60). Dengan konsep socio-democratie, Soekarno ingin agar masyarakat Indonesia tidak hanya setara di bidang politik, tapi juga di dalam bidang ekonomi. Usaha Soekarno tersebut sekaligus dapat menjadi pintu masuk bagi bidang pendidikan bangsa Indonesia untuk melepaskan dominasi hegemoni "studi" dari bangsa Barat. Sebagaimana dijelaskan oleh Said (2010) bahwa selain menghilangkan jati diri dan kepribadian bangsa terjajah, praktik kolonialisme juga mendominasi "studi" atas bangsa Timur yang ala kadarnya. Dikatakan ala kadarnya karena para "ahli" dari Barat merekonstruksi dan mensistematisasi dunia Timur menurut 
apa yang "seharusnya", bukan "sebagaimana adanya" dunia Timur. Pola yang seperti ini terjadi sedemikian lama dan terus berevolusi sehingga pada akhirnya menciptakan garis batas epistemologis, yakni superioritas dan inferioritas (Bhabha, 1990). Soekarno berupaya mengangkat martabat bangsa Indonesia di hadapan bangsa Barat melalui prinsip internasiolisme, yakni martabat politik, martabat ekonomi, dan martabat intelektualitas atau pendidikan bangsa Indonesia.

\section{Nilai “Otentik?" Bangsa Indonesia dalam Third space of Communication Pidato 1 Juni 1945}

Pada pidato 1 Juni 1945, Soekarno seolah tidak menawarkan sama sekali ideologi dari luar bangsa sebagai jati diri Indonesia. Ideologi berhaluan liberalis dan sosialis secara eksplisit sama sekali tidak disinggung, padahal secara pribadi Soekarno pernah kagum terhadap praktik demoraksi liberal dan sosialisme sebagai metode berpikir untuk menyerang praktik kolonialisme (Soekarno, 1964a). Dalampidato 1 Juni 1945, alihalih Soekarno mengekplorasi ideologi luar untuk mendefinisikan jati diri bangsa, bahkan Soekarno menawarkan refleksi khas yang memuat nilai keIndonesia-an, sebagaimana ungkapan berikut:

"Philosofische grondslag itulah fundamen, filsafat, pikiran yang sedalam-dalamnya, jiwa, hasrat yang sedalam-dalamnya untuk di atasnya didirikan gedung Indonesia Merdeka yang kekal dan abadi" (Soekarno, 1964a:33).

Pada pidato 1 Juni 1945, Soekarno tidak menyebutkan secara eksplisit nilai atau idelogi Barat, namun tudi dari Latif (2011) menunjukan bahwa pidato 1 Juni 1945 dari Soekarno merupakan sintesis kreatif dari Declaration of American Independence (dari kapitalisme) dan Manifesto Komunis (dari komunisme). Jadi, memberikan klaim gagasan Soekarno sebagai nilai otentik yang digali dari bangsa Indonesia tidak cukup kuat dengan fakta kajian akademis yang ada. Arah gagasan Soekarno dalam pidato 1 Juni 1945 dinilai sebagai upaya untuk lebih memenuhi kebutuhan dan menyelamatkan masyarakat Indonesia dengan memadukan karakteristik kultural bangsa Indonesia dengan Declaration of Independence-nya Amerika Serikat (Kapitalisme) dan Manifesto Komunis (Komunisme). Declaration of Independence tidak mengandung Keadilan Sosial; adapun Manifesto Komunis tidak mengandung Ketuhanan Yang Maha Esa. Oleh karena itu, harus disublimir dengan Ketuhanan Yang Maha Esa agar tidak terpenjara dalam berhala materialisme (Latif, 2011). Dengan perpaduan nilai-nilai tersebut memunculkan salah satu identitas bangsa Indonesia yakni yang berkeTuhanan.

Terkait dengan nilai ketuhanan, Soekarno bergulat dengan pemikiran dirinya sendiri. Nilai-nilai Ketuhanan sudah mendarah daging dalam diri Soekarno karena neneknya memberi pengajaran tentang mistisisme Jawa, dan melalui ayahnya Soekarno belajar teosofi dan Islam. Sedangkan dari ibunya, Soekarno belajar agama Hindu dan Buddha sekalipun Soekarno memeluk agama Islam, tetapi Soekarno terbuka terhadap dialog dengan agama lain dan tidak memaksakan agar Islam menjadi agama nasional. Hal tersebut dapat dipahami dari perjalanan intelektual Soekarno yang juga dipengaruhi oleh Mustafa Kemal Attaturk, pendiri Turki modern yang memisahkan agama dengan negara atau disebut dengan paham sekularisme (Ismail, 2018). Temuan ini, sekaligus menunjukan ada "darah" sekularisme dalam bangsa Indonesia yang tertuangkan dari gagasan-gagasan Soekarno yang dipengaruhi oleh Mustafa Kemal Attaturk.

Ciri khas utama dari Soekarno yang memadukan beragam pemikiran kekayaan gagasan tentang Ketuhanan sebagai identitas bangsa Indonesia, Soekarno memiliki sintesis khas ketika harus mendefinisikan siapa itu bangsa Indonesia dari perspektif Ketuhanan. Soekarno melihat bahwa Indonesia adalah bangsa yang bertuhan sejak zaman pra-Hindu, Indonesia hidup dalam alam pemujaan. Sejak zaman Islam, Indonesia hidup dengan Ketuhanan Yang Maha Esa, begitu juga agama atau pun kepercayaan 
lain yang berada di nusantara. Dalam hal ini, Soekarno meyakini bangsa Indonesia yakin dan percaya bahwa ada Yang Transenden yang menguasai hidup mereka (Soekarno, 1964b).

Terkait dengan musyawarah-mufakat, Soekarno menilai bahwa musyawarah-mufakat adalah jiwa kepribadian rakyat Indonesia (Soekarno, 1964b). Sukardi (2019) menilai bahwa musyawarah-mufakat juga menjadi nilai semangat masyarakat Asia (termasuk Indonesia), yang berkaitan dengan harmonisasi dan kerakyatan. Soekarno mengetahui bahwa halangan terbesar dari kemerdekaan Indonesia adalah pengaruh nilai dari kapitalismeimperialisme dari yang berakar dari Barat. Pemaksaan nilai yang monologis dan canonical ini tidak akan pernah berjalan dengan baik di Indonesia karena corak masyarakat Indonesia (dan Asia) itu identik dengan harmonisasi dan keteraturan sosial (Dahm \& van der Kroef, 1969). Soekarno menawarkan gagasan musyawarahmufakat menjadi salah satu identitas bangsa Indonesia untuk mencapai harmonisasi dan keteraturan sosial, sehingga tidak menimbulkan perpecahan bangsa dan jalan menuju persatuan di antara beragamnya perbedaan.

Terkait dengan demokrasi ekonomi, Soekarno pada mulanya tertarik dengan ide demokrasi "ala Barat", karena di dalamnya ada kesetaraan yang diperjuangkan di dalam gedung parlemen. Pemikiran demokrasi "ala barat" tidak bisa dilepaskan dari konteks zaman Soekarno yang pada saat itu ada jurang pemisah antara rakyat Indonesia yang menjadi buruh di negara sendiri dan penjajah yang menjadi majikan (Soekarno, 1946b). Untuk mengatasi masalah tersebut, Soekarno menawarkan konsep demokrasi ekonomi dengan beradu gagasan di gedung parlemen untuk memperjuangkan kepentingan rakyat, dan utamanya kesejahteraan ekonomi rakyat yang pada masa itu terpuruk akibat kolonialisme bangsa asing.
Gagasan Ketuhanan, musyawarah-mufakat, dan demokrasi ekonomi yang ditawarkan oleh Seokarno memiliki implikasi penting dalam third space of communication untuk membangun identitas bangsa Indonesia yang tersusun atas beragam agama, kepentingan dan kelas sosial. Dengan tiga nilai tersebut, Soekarno mengangkat setiap perbedaan tadi ke dalam satu wadah yang sama yakni Indonesia. Usaha Soekarno untuk merangkul dan memberikan tempat bagi setiap perbedaantidaklepasdarilatarbelakanghidupnya. Selama hidup, Soekarno bersinggungan dan belajar nilai-nilai serta ideologi yang berbedabeda, dan bahkan bertentangan. Sebagaimana hal tersebut dibuktikan dalam kutipan berikut: "To that I added gleanings of Karl Marxism and Thomas Jeffersonism. I learned economics from Sun Yat-sen, benevolence from Gandhi. I was able to synthesize modern scientific schooling with ancient animistic culture and to translate the end product into living, breath-ing messages of hope geared to the understanding of a peasant. What came out has been called - in plain termsSukarnoism." (Adams, 1965, hal. 71).

Ada beberapa nilai yang tidak terkait langsung dengan jati diri bangsa Indonesia, namun Soekarno selalu mengontekstualisasikan nilai-nilai yang diserapnya dengan kondisi aktual di Indonesia. Misal, alih-alih Soekarno menggunakan istilah proletar untuk menggambarkan kondisi rakyat Indonesia yang menjadi buruh di negeri sendiri, Soekarno menggunakan istilah marhaen yang di kemudian hari dikenal dengan istilah marhaenisme sebagai jalan pikiran Soekarno untuk mengentaskan kemiskinan di Indonesia. Hal yang sama lakukan oleh Soekarno ketika merevisi demokrasi Barat menjadi demokrasi ekonomi agar sesuai dengan kondisi Indonesia. Terkait hal ini, Soekarno mengakui bahwa dirinya sanggup membuat sintesis atas ilmu-ilmu modern dengan kebudayaan animistik purbakala lalu membahasakannya agar sesuai dengan konteks masyarakat (Adams, 1965). Jadi, gagasangagasan dari Soekarno terkait identitas bangsa 
Indonesia yang dituangkan dalam pidato 1 Juni 1945, dapat memunculkan pertanyaan baru apakah gagasan Soekarno merupakan murni digali dari karakteristik bangsa Indonesia? sehingga menjadi nilai "otentik" bangsa Indonesia. Atau gagasan dari Soekarno merupakan perpaduan dari berbagai pemikiran atau ideologi tokoh dunia? sehingga menyebut nilai "otentik" bangsa Indonesia sebagai sebuah kenaifan.

\section{Gagasan Soekarno sebagai Pengayaan Konsep Third Space of Communcation dari Homi K. Bhabha}

Pidato 1 Juni 1945 yang dicetuskan Soekarno memuat nilai-nilai yang menjadi identitas bangsa Indonesia yang pada akhirnya diarahkan menuju persatuan di antara beragam perbedaan. Soekarno berhasil membangun ruang komunikasi bersama yang menjadi jembatan bagi perbedaan nilai, latar belakang dan kebudayaan sekaligus mengarahkannya pada penemuan nilai bersama di antara keberagaman untuk membentuk identitas bangsa Indonesia yang terkubur akibat penjajahan. Selain itu, Soekarno juga memiliki keberanian untuk mengangkat nilai-nilai hasil sintetis dari nilai yang saling bertentangan yang akhirnya menghasilkan gagasan baru dan menjadi identitas bangsa Indonesia, seperti ketuhanan, gotong-royong, dan musyawarah mufakat. Usaha Soekarno untuk mengangkat dan mempersatukan nilai-nilai tersebut adalah upaya untuk melawan hegemoni penjajahan. Menurut Spivak (dalam Gandhi, 1998:55) hal tersebut merupakan bentuk dari valorisation of marginality dan menjadi hal yang wajar terjadi di negara-negara terjajah seperti di Indonesia.

Valorisation of marginality dinilai dapat menggemakan kembali nilai-nilai yang pudar akibat dominasi penjajahan. Namun, valorisation of marginality juga perlu dikritik karena hanya akan memperuncing pertentangan antara nilai-nilai "dominan" (berasal dari penjajah) dan nilai-nilai yang terpinggirkan (berasal dari pihak terjajah), sehingga yang terjadi adalah pola dikotomi hitam-putih dan klaim sepihak bahwa nilai-nilai yang berasal dari bangsa-ku adalah yang terbaik (Spivak dalam Gandhi, 1998). Hal tersebut terlihat telah disadari oleh Soekarno sehingga dirinya membahas tentang chauvinisme seperti berikut:

"Bahayanya ialah mungkin orang meruncingkan nasionalisme menjadi chauvinisme, sehingga berfaham "Indonesia uber Alles". Inilah bahayanya! Kita cinta tanah air yang satu, merasa berbangsa yang satu, mempunyai bahasa yang satu. Tetapi Tanah Air kita Indonesia hanya satu bahagian kecil saja dari pada dunia! Ingatlah akan hal ini! [...] Kita bukan saja harus mendirikan negara Indonesia Merdeka, tetapi kita harus menuju pula kepada kekeluargaan bangsabangsa" (Soekarno, 1964b: 24).

Merujuk kutipan tersebut, Soekarno tidak lagi mempertentangkan begitu saja nilai-nilai dari Indonesia untuk melawan hegemoni Barat. Soekarnotidakmemraktikkanpolapikirdikotomis hitam-putih yang pernah dipraktikkan penjajah. Lebih jauh, Soekarno hendak menyejajarkan Indonesia dengan bangsa-bangsa lain. Pada akhirnya, stereotip penjajah yang mengatakan bahwa Indonesia itu "inlander seperti kerbau, inlander goblok, inlander bodoh" (Soekarno, 1946a) dapat diakhiri dengan upaya Soekarno membangun third of space communication dalam rangka membentuk identitas bangsa Indonesia. Hal lainnya, third of space communication yang dibangun oleh Soekarno menjadi ruang bersama untuk menampung keragaman ide dan gagasan dalam rangka mengisi kemerdekaan yang disebut dengan "jembatan emas" untuk mengantarkan Indonesia sebagai negara yang gagah, kuat, kekal, dan abadi setelah terlepas dari belenggu penjajagan kolonial (Soekarno, 1964b:15).

Dalam usaha membangun third space of communication untuk membentuk identitas bangsa Indonesia, Soekarno tidak menghilangkan keragaman bangsa Indonesia dan tetap memberikan ruang terhadap setiap kebudayaan untuk mengaktualisasikan dirinya (Sari \& Krisnawati, 2017), tercermin saat 
Soekarno menyinggung sesuatu yang bersifat kedaerahan seperti "Minangkabau, Yogyakarta, dan Pasundan atau Sunda", tetapi pada akhirnya diarahkan kepada wadah persatuan yakni Indonesia (Soekarno 1946a; 1946b). Gagasan Soekarno tersebut berbeda dengan gagasan third space of communication dari Homi K. Bhabha yang mensyaratkan persatuan dapat dicapai dengan mengaburkan (bahkan menghilangkan) fixedness dari kebudayaan asli (Bhabha, 1994; Zhou \& Pilcher, 2019). Secara jelas, Soekarno dalam membangun third space of communication tidak ingin mengaburkan fixedness keragaman kebudayan Indonesia, apabila hal tersebut dilakukan justru berpotensi menimbulkan pertentangan atau pun fanatisme budaya, agama atau kepercayaan, etnis, suku, dan ras yang begitu beragam di Indonesia. Sebagaimana dijelaskan oleh Raj (2014) bahwa pengaburan fixedness dapat menimbulkan bahaya, yakni pelupaan sejarah (neglegance of history) dan bertendensi untuk jatuh dalam narasi fanatisme etnis. Peneliti menilai bahwa naskah pidato Soekarno 1 Juni 1945 harus dibongkar lebih mendalam melalui penelusuran tokohtokoh yang berkontribusi dalam penyusunan naskah tersebut. Tokoh Mohammad Yamin dan Soepomo merupakan tokoh yang sangat dekat dengan Soekarno pada saat sidang BPUPKI yang pada akhirnya melahirkan Pancasila.

\section{Simpulan}

Melalui pidato 1 Juni 1945, Soekarno mengingatkan bahwa Indonesia adalah bangsa yang bermartabat, berdikari, berkepribadian, dan setara dengan bangsa-bangsa lain yang berusaha diwujudkan melalui internasionalime. Soekarno juga membuktikan bahwa beragam nilai yang dimiliki oleh bangsa Indonesia tidak bisa dijadikan alasan untuk memisahkan diri, karena bangsa Indonesia memiliki satu kepribadian, yakni gotong-royong. Persatuan menjadi nilai yang diusung dan diperjuangkan oleh Soekarno sebagai entitas utama bangsa Indonesia dalam third space of communication. Persatuan bukan dalam rangka meleburkan keberagaman seperti dikonsepsikan oleh Bhabha, tetapi persatuan dalam rangka mewadahi keberagaman bangsa Indonesia.
Usaha mencapai sintesis dari beragam nilai dan gagasan menjadi ciri khas third space of communication yang dibentuk oleh Soekarno. Di dalam pemikiran Soekarno, penemuan gotong-royong sebagai kepribadian bangsa tidak akan menghapus nilai-nilai dasar yang membentuknya yakni keberagaman bangsa Indonesia. Di dalam gotong-royong, warisan praktik pengotakkan identitas yang dilakukan oleh pemerintah kolonial ditinggalkan dan setiap elemen bangsa diajak untuk membangun imaji kesatuan yang lebih luas sebagai suatu bangsa yang hendak mencapai kemerdekaan.

Penelitian ini menemukan nilai "otentik" yang ditawarkan oleh Soekarno dalam membangun identitas bangsa Indonesia. Sekaligus temuan tersebut menjadi batasan penelitian karena terdapat refleksi untuk mempertanyakan asal muasal munculnya gagasan Soekarno tentang nilai-nilai otentisitas bangsa Indonesia. Selanjutnya perlu diteliti lebih lanjut keterkaitan antara pemikiranpemikiran ideologi asing dengan karakteristik Indonesia dalam gagasan Soekarno. Dengan keterbatasan tersebut, penelitian selanjutnya diharapkan menelusuri genealogi pemikiran Soekarno dalam membentuk identitas bangsa atau pun Pancasila sebagai dasar negara. Metode penelitian selanjutnya yang digunakan dapat memadukan analisis lingkar hermeneutika dari Gadamer dan arsitektur pengetahuan dari Foucault sehingga mendapatkan temuan yang dapat melengkapi keterbatan penelitian ini.

Hasil penelitian ini berkontribusi dalam pengayaan konsep third space of communication yang diusung Hommi K. Bhabha dalam kajian Ilmu Komunikasi di Indonesia. Gotong royong sebagai identitas keindonesian bukan merupakan sebuah perwujudan dari konsep hibriditas yang dijelaskan Bhabha, namun gotong royong merupakan nilai otentik yang mampu mempertahankan keberagaman dan sekaligus keberagaman tersebut akan memperkuat semangat gotong royong. 


\section{Daftar Pustaka}

Adams, C. (1965). Sukarno; an Authobiography as Told to Cindy Adams. Toppan Printing.

Anderson, B. (2006). Imagined Communities. Verso. https://doi.org/10.2307/j.ctvgs0c0q.10

Bhabha, H. (1990). Nation and Narration. Routledge.

Bhabha, H. (1994). The Location of Culture (H. Bhabha, Ed.). Routledge. https://doi. org/10.1017/CBO9781107415324.004

Cook, V., \& Wei, L. (2009). Contemporary Applied Linguistic; Language Teaching and Learning (V. Cook \& L. Wei, Eds.). Continuum.

Dahm, B., \& van der Kroef, J. (1969). Soekarno: the Ideologue. Pacific Affairs, 42(1), 55-57. https://doi.org/https://doi. org $/ 10.2307 / 3350794$

Darby, P. (2018). The multiple identities of the postcolonial: Tracking the making of our project. Postcolonial Studies, 21(3), 271277. https://doi.org/10.1080/13688790.201 8.1493967

Dewantara, A. (2015). Pancasila dan Multikulturalisme Indonesia. Studia Philosophica et Theologica, 15(2), 109-126. https://doi.org/10.31227/osf.io/8r7h9

do Mar Castro Varela, M., \& Tamayo Rojas, C. (2020). Epistemicide, postcolonial resistance and the state. Postcolonial Studies, 23(2), 226-240. https://doi.org/10.1080/13688790 .2020 .1751913

Fennell, C. (2018). Beyond the trace. Postcolonial Studies, 21(4), 520-524. https://doi.org/10.1 080/13688790.2018.1542581

Gadamer, H.-G. (2004). Truth and Method (2nd ed.). Continuum.

Galvan-Alvarez, E., Laursen, O. B., \& Ridda, M. (2020). Decolonising the state: subversion, mimicry and criminality. Postcolonial Studies, 23(2), 161-169. https://doi.org/10.1 080/13688790.2020.1752356

Gandhi, L. (1998). Postcolonial Theory; A Critical Introduction. Allen \& Unwin. https://doi.org/10.4135/9781412956246. n435
Habermas,J.(1987). The TheoryofCommunicative Action; Lifeworld and System: a Critique of Functionalist Reason. Beacon Press. https:// doi.org/10.4324/9780203020166-6

Hargens, B. (2019, November 6). Merawat Ingatan. Kompas, 6.

Huddart, D. (2006). Homi K. Bhabha. Routledge. https://doi.org/10.1007/978-3-476-053862_3

Huddart, D. (2007). Postcolonial Theory and Autobiography. Routledge. https:/doi. org/10.4324/9780203306574

Ismail, F. (2018). Religion, State, and Ideology in Indonesia: a Historical Account of the Acceptance of Pancasila As the Basis of Indonesian State. Indonesian Journal of Interdisciplinary Islamic Studies, 1(2), 1958. https://doi.org/10.20885/ijiis.voll.iss2. art2

Jaya, I. (2016). Nalar pancasila dalam komunikasi politik. Jurnal Komunikasi, 13(2).

Jensen, K. B. (2018). The Double Hermeneutics of Communication Research. Javnost - The Public, 25(1-2), 177-183. https://doi.org/10 $.1080 / 13183222.2018 .1418968$

Latif, Y. (2018a). Identitas Keindonesiaan dan Aktualisasi Pancasila bagi Generasi Milenial di Era Digital. Jurnal Kajian Lemhannas RI, 33, 5-19. http://jurnal.lemhannas.go.id/ index.php/jkl/article/view/112

Latif, Y. (2018b). Religiosity, Nationality, and Sociality of Pancasila: Toward Pancasila through Soekarno's Way. Studia Islamika, 25(2), 207-246. https://doi.org/10.15408/ sdi.v25i2.7502

Liberman, K. (1984). Trustees of Indiana University Anthropological Linguistics. The Hermeneutics of Intercultural Communication, 26(1), 53-83.

Mahfud, M. D. (2020, January 1). Tidak Ada Islamofobia di Indonesia. Kompas, 6.

McLeod, J. (2007). The Routledge Companion to Postcolonial Studies (J. McLeod, Ed.). Routledge. https://doi. org/10.4324/9780203358085 
Mueller-Vollmer, K. (Ed.). (1987). The Hermeneutics Reader (Vol. 38, Issue 3). Continuum. https://doi.org/10.2307/590701

Palmer, R. E. (1969). Hermeneutics; Interpretation Theory in Schleiermacher, Dilthey, Heidegger, and Gadamer. Northwestern University Press. https://doi. org/10.4135/9781483347660.n326

Pamungkas, P. (2018). Lingkaran hermeneutika dan pancasila. Caritas pro Serviam, 36(1), 16-27.

Pawito, P., Muktiyo, W., \& Arifin, H. (2020). Nilai Budaya dan Gaya Komunikasi Warga Minangkabau, Jawa, dan Bugis. Jurnal Ilmu Komunikasi, 17(3), 249. https://doi. org/10.31315/jik.v17i3.3775

Raj, P. P. E. (2014). Postcolonial Literature , Hybridity and Culture. International Journal of Humanities \& Social Science Studies (IJHSSS), 1(2), 125-128. http://www.ijhsss. com

Rangan, P., \& Chow, R. (2013). Race, Racism, and Postcoloniality. The Oxford Handbook of Postcolonial Studies, September, 1-12. https://doi.org/10.1093/ oxfordhb/9780199588251.013.0025

Rodriguez, A. (2018). A case against colonialism. Postcolonial Studies, 21(2), 254-259. https://doi.org/10.1080/13688790.2018.147 4705

Romadlan, S. (2020). Diskursus Negara Pancasila di Kalangan Muhammadiyah. Sospol: Jurnal Sosial Politik, 6(1), 1-15. https://doi. org/10.1017/CBO9781107415324.004

Rutazibwa, O., \& Shilliam, R. (2012). Routledge Handbook of Postcolonial Politics (O. Rutazibwa \& R. Shilliam, Eds.). Routledge. https://doi.org/10.4324/9780203148433

Rutherford, J. (Ed.). (1990). Indentity; Community, Culture, Difference. Lawrence \& Wishart. https://doi.org/10.16309/j.cnki. issn.1007-1776.2003.03.004

Said, E. (2010). Orientalisme; Menggugat Hegemoni Barat dan Mendudukkan Timur sebagai Subjek. Pustaka Pelajar.
Sari, D. K., \& Krisnawati, E. (2017). The Spread of Nationalism using Social Media. Jurnal Ilmu Komunikasi, 15(3), 226. https://doi. org/10.31315/jik.v15i3.2174

Seran, A. (2015). Hermeneutika sebagai Acuan Kritik Ideologi Sejarah Orde Baru. Respons, 20(2), 145-185.

Shanguhyia, M. S., \& Falola, T. (2018). The Palgrave handbook of African colonial and postcolonial history. In The Palgrave Handbook of African Colonial and Postcolonial History. Palgrave Macmillan. https://doi.org/10.1057/978-1-137-59426-6

Siswoyo, D. (2013a). Pandangan Bung Karno Tentang Pancasila Dan Pendidikan. Jurnal Cakrawala Pendidikan, 5(1), 103-115. https://doi.org/10.21831/cp.v5i1.1264

Siswoyo, D. (2013b). Philosophy of education in Indonesia: Theory and thoughts of institutionalized state (Pancasila). Asian Social Science, 9(12), 136-143. https://doi. org/10.5539/ass.v9n12p136

Soekarno. (n.d.). Indonesia Menggugat. Departemen Penerangan RI.

Soekarno. (1964a). Di Bawah Bendera Revolusi. Departemen Penerangan RI.

Soekarno. (1964b). Tjamkan Pantjasila. Departemen Penerangan RI.

Syahputra, A. (2015). Pemikiran Pluralisme Ir. Soekarno. Universitas Islam Negeri Sunan Kalijaga.

Widdowson, H. G. (2004). Text, Context, Pretext: Critical Issues in Discourse Analysis. In Text, Context, Pretext: Critical Issues in Discourse Analysis. Blackwell Publishing. https://doi.org/10.1002/9780470758427

Widdowson, H. G. (2007). Discourse Analysis. Oxford University Press.

Winartono, W., Antoni, A., \& Sujoko, A. (2019). Membumikan Ilmu Komunikasi di Indonesia (Pembacaan Hermeneutik Gadamerian atas Tulisan-Tulisan M. Alwi Dahlan). Mediakom, 2(2), 100. https://doi. org/10.32528/mdk.v2i2.1922 
Young, R. J. C. (2003). Postcolonialism: A Very Short Introduction. Oxford University Press. Yunaldi,W.(2020). The Dynamic Interpretation of Pancasila in Indonesian State Administration History: Finding Its Authentic Interpretation.
Jurnal Hukum Novelty, 11(1), 39. https://doi. org/10.26555/novelty.v11i1.a15166

Zhou, V. X., \& Pilcher, N. (2019). Tapping the thirdness in the intercultural space of dialogue. Language and Intercultural Communication, 19(1), 23-37. https://doi.org/10.1080/14708477 .2018 .1545025 